\title{
What really makes students like a web site? What are the implications for designing web-based language learning sites?
}

\author{
JANE HUGHES, CLAIRE MCAVINIA AND TERRY KING \\ Department of Education and Professional Development, University College London \\ 1-19 Torrington Place, London WC1E 6BT, UK \\ (email: \{jane.hughes,claire.mcavinia,terry.king\}@ucl.ac.uk)
}

\begin{abstract}
Faced with reduced numbers choosing to study foreign languages (as in England and Wales), strategies to create and maintain student interest need to be explored. One such strategy is to create 'taster' courses in languages, for potential university applicants. The findings presented arise from exploratory research, undertaken to inform the design of a selection of web-based taster courses for less widely taught languages. 687 school students, aged 14-18, were asked to identify a web site that they liked and to state their main reason for liking it. They were invited to include recreational sites and told that their answers could help with web design for the taster courses. To explore the reasons, two focus groups were conducted and student feedback on the developing taster course site was collected. Students nominated search engines and academic sites, sites dedicated to hobbies, enthusiasms, youth culture and shopping. They liked them for their visual attributes, usability, interactivity, support for schoolwork and for their cultural and heritage associations, as well as their content and functionality. They emerged as sensitive readers of web content, visually aware and with clear views on how text should be presented. These findings informed design of the taster course site. They are broadly in line with existing design guidelines but add to our knowledge about school students' use of the web and about designing web-based learning materials. They may also be relevant to web design at other levels, for example for undergraduates.
\end{abstract}

\section{Introduction}

\subsection{Research context}

This paper reports research undertaken as part of the ATLAS (A Taste of Languages at School) project. The project was conceived in year 2000 in a climate of concern about the take-up of modern foreign languages (MFL) in the upper years of secondary school and in first-degree courses, in England and Wales.

Table 1 shows the decline in entries for Advanced (A) level ${ }^{1}$ examinations, between 1994 and 2000, for the most widely taught modern foreign languages, French, German and Spanish. 
Table 1. A level candidates in French, German, Spanish 1994/2003

(Source: The Joint Council for General Qualifications (JCGQ)

\begin{tabular}{lll}
\hline \hline & 1994 & 2003 \\
\hline Number of entries & 44,514 & 28,345 \\
$\%$ of all A level candidates & $6.07 \%$ & $3.77 \%$ \\
\hline \hline
\end{tabular}

In 2000, Curriculum 2000 was introduced in England and Wales in an attempt to broaden the curriculum for 16-19 year olds. From this point on, the typical student would study five instead of three subjects, taking five Advanced Supplementary (AS) levels in the first year and continuing three of these to A2 (previously A) level in the second year. Table 2 shows entries in MFL at AS level since then, as a percentage of entries in all AS subjects. In 2001, the number taking the new AS in a MFL was 39,084 in contrast to 3671 in the previous year. However, 2001-03 figures include students on two-year A level courses, whose examination entries were, prior to this, recorded separately.

Entrance to Higher Education for courses with a significant MFL component has declined by around $4.5 \%$ annually since the early 1990s. From 1997 to 2001 it fell by $22.45 \%$. Language degrees have lost a third of their market share (3.4\% to 2.4 ).

\subsection{Research aims}

The ATLAS project was established to find out whether web-based foreign language tasters could foster positive attitudes towards language learning amongst school students. The project would begin by surveying students in the upper years of secondary school (that is, aged 14-18) on their attitudes towards and experiences of learning languages. Then, informed by the results of the survey (see http://www.ucl.ac.uk/epd/ atlas/atlas-questionnaire-report.htm), language teachers would work with a web developer to create on-line tasters in less widely taught languages. The tasters would contain a language-learning element but were not intended to be beginners' language courses. Less widely taught languages were chosen because it was felt that they might provide a fresh start for those whose previous language learning experience had discouraged them.

The key aims of the tasters were to motivate, enthuse and interest. It was recognised that a successful experience of learning would be essential in achieving these aims but questions remained about what would be needed in addition to the pedagogical requirements.

It was believed that an exploratory study was needed, to increase understanding of how the target groups for the language tasters used the web. Of particular interest were the kinds of sites and designs that appealed to this group and the factors that might attract them to a web site, since it seemed possible that the 'look and feel' of the language tasters could be important in promoting the languages. The research reported here was intended to explore these areas and to inform web design for the language tasters.

1 Advanced (A) level courses are followed by UK students in their last two years at school and are aimed at those intending to apply to university. 


\subsection{Existing design frameworks for web-based material}

In tandem with the planning of the exploratory study with students, the members of the project team also discussed their own existing approaches to the web and to developing materials for the web. These approaches were influenced by the literature on web design, which in turn offers many different perspectives influenced by different design specialisms, including:

- Web usability (e.g. Nielsen, 2000)

- Instructional design (e.g. Ritchie \& Hoffman, 1996)

- $\quad$ Graphic design (e.g. Weinman, 2003)

- Web design for commercial websites (e.g. Goto \& Cotler, 2002).

Guidelines for the design of open and distance learning materials (Rowntree, 1994) have also been applied to the design of web-based learning materials.

While all the approaches and associated texts listed above are of great importance and have much to offer, they represent very different perspectives on the process of designing materials for the web, and many do not consider web design for educational purposes. Teachers seeking to create new web-based resources for their students may refer to any or all of the key texts for each of the approaches listed above. In addition, they may have tailored guidance material provided by their institutions and itself influenced by whichever approaches its authors have favoured, or have used in learning about the web themselves. However, the work we describe here indicated that elements of all these and other design approaches were needed to plan and create a resource that would be attractive to current school students and potential future higher education students. In addition, some existing aspects of practice were challenged by our findings.

Another factor we began to consider during the course of the project was that of visual literacy, and the importance of visual awareness in designing web-based materials for learning and teaching. Emerging research into visual literacy (Kress, 1998; Honeywill, 1999; Brown, 2002) suggests that new technologies have foregrounded visual elements to an extent unknown since the era of hieroglyphics. The research suggests that it is only through developing our own sensitivity and awareness of visual elements (including icons, fonts for text, colours, images), and the ways in which these are read, that we will be able to design for a generation which has grown up in a visual culture. This theme will be returned to later in discussion of the design decisions taken on the basis of our research.

\section{Research methods}

A commitment to user-centred design in the whole ATLAS project governed this research. User-centred design evolved out of the Participatory Design movement, which originated in European countries with a strong trade union tradition and an interest in the social aspects of introducing technology into the workplace. Originally intended for the design of large industrial systems, it has diversified and is now also applied to the design of smaller-scale software systems, including educational software (e.g. Hinostroza \& Mellar, 2001) and web-based learning materials (e.g. Hémard \& Cushion, 2001). 
Table 2. AS level candidates in a MFL 2001/2003 (Source JCGQ)

\begin{tabular}{llll}
\hline \hline & 2001 & 2002 & 2003 \\
\hline Number of AS entries in a MFL & 39,084 & 45,922 & 44,731 \\
$\%$ of all AS level candidates & $4.76 \%$ & $4.61 \%$ & $4.34 \%$ \\
\hline \hline
\end{tabular}

In terms of method, Participatory Design does not prescribe a set of steps to be followed. Instead, the designer-researcher can select from a variety of methods that are designed to empower end users to participate in design decisions. Muller et al. (1993) present a taxonomy of practices. Kensing and Munk-Madsen (1993) and Wall and Mosher (1994) also review methods. Typical techniques include unstructured interviews, group discussions and workshops, graphical techniques to aid visualisation, and prototyping.

In this case, a prototype was developed early in the project, and refined through repeated cycles of design, development and evaluation (see Figure 1). Alongside this, questionnaires and focus groups were used to capture students' experiences and opinions, with the research becoming progressively more fine-grained. An initial questionnaire was used to gain an overview of the kinds of web sites students liked and an outline sketch of factors that attracted them. Focus groups then enabled a fuller exploration of issues that emerged from the questionnaire. Finally, students were asked to comment on the developing taster web site and specific areas of interest that the focus groups had revealed.

Figure 1 summarises the sequence. It also sketches in the parallel strand of user involvement that is not reported here. The subject of this paper is the students' views and perceptions, and the focus is on design, but teachers' views were also considered essential to the site's development. As already stated, pedagogy was considered one key to creating a satisfying experience for the students. In addition to the work described here, a group of language teachers from the project's partner schools was asked to evaluate the developing site from a pedagogical viewpoint.

Focus groups (Lunt \& Livingstone, 1996; Morgan, 1998) were chosen because they are means of understanding issues that matter to the participants and are suited to identifying problems that need to be addressed, to enable improvements to implementation (Morgan, 1998). This would be useful for evaluating the evolving prototype web site. In addition, a focus group is, "a friendly, respectful research method" (Morgan, 1998: 59), which is in keeping with a user-centred approach.

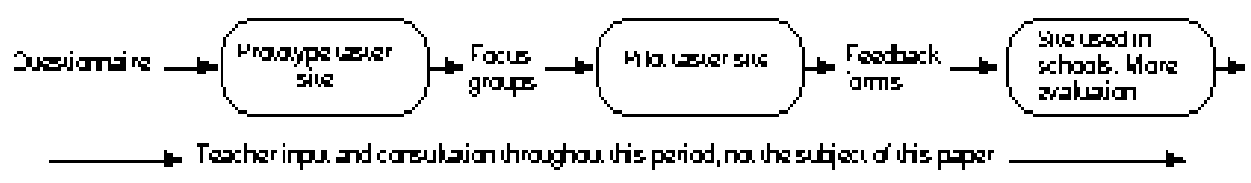

Fig. 1. Sequence of research. 


\subsection{Questionnaire}

A questionnaire was distributed to nine schools and returned by 687 students, aged 14-18. Alongside questions related to language learning, students were also asked to identify a web site that they liked and to state their main reason for liking it. They were invited to include recreational sites and, because many of the other questions concerned language learning, they were told that the site need not be related to languages. They were also told that their answers could help with web design. The aim was to gain an overview of websites that students liked and an outline sketch of what attracted them.

Language teachers from the schools were consulted over the content and wording of the questionnaire. It was then piloted in two schools. The final version was administered by staff from the schools, who had been briefed by the project team. The students completed the questionnaire anonymously but they did have the option to volunteer to take part in a focus group. Those who did so were asked to give their names. The questionnaire data was analysed as follows:

1. Three researchers took a year group each and worked independently. They found each nominated site, bookmarked it and added it to a list for that year group, then wrote a short identifier of the type of site, to categorise it.

2. All the reasons students had given for liking a site were also listed.

3. The research team met. The lists of site identifiers (that is, types of site) were compared and rationalised. The lists of reasons were discussed and a tentative list of categories for analysing these was agreed. Two members of the team then independently assigned all the reasons to the agreed categories. As a result of this process, it was decided to reduce the number of categories of reason. This simplified the analysis in one sense but led to the creation of several sub-categories (see Section 3.2). Figure 2 shows the final list of categories used.

Fewer than half of all students surveyed named a web site. Some possible reasons for this are considered in Section 4. It was anticipated that inaccurate URLs or illegible handwriting might make it difficult to find sites that students had named in the questionnaire. In practice only three sites were not identified. When it came to analyzing the reasons students gave, there were a few problem areas. Four students gave as a reason the

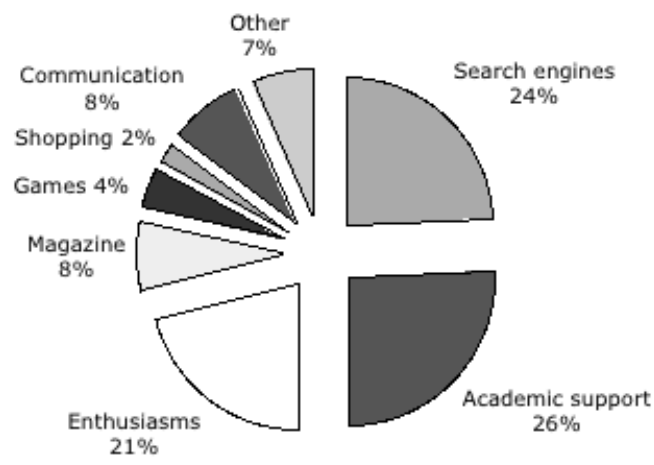

Fig. 2. Types of site liked (questionnaire) 
fact that the site was "good" and one stated that it was "wicked". No attempt was made to interpret these responses; they were assigned to their own category, Unspecific Praise. Six stated that a site was, "interesting". In this case, reference was made to the site they had named and, in every case, it was concluded that it was the content that they found interesting. Two students gave no reason for nominating their sites.

\subsection{Focus groups}

Two focus groups were conducted. Group One consisted of six year twelve students (age 16-17), four female, two male. Group Two consisted of five year ten/eleven students (age 15-16), two female, three male. Both groups were audio-recorded, with the students' permission. The students were given $£ 5.00$ vouchers to acknowledge their contribution to the research.

The agenda for the focus groups was drawn up by two members of the research team, R1 and R2. Group One was conducted by R1, with R2 attending. Group Two was conducted by R1.

The process for the two groups differed. In trying not to inconvenience the host school, the first focus group was conducted in a classroom without computers. Not surprisingly, that group of students, without examples on screen to refer to, found it harder than the second group to talk about web sites they used. It was felt that the second group, who had Internet access and could look at the sites they were talking about, was able to make more precise comments than the first. The discussions were conducted as follows:

1. The facilitator explained the context, that is, development of the ATLAS project taster web site. The explanation covered:

- The project's aim: to investigate the decline in the number learning languages.

- The taster site design brief: it must appeal to years 10-12/13 and must interest them in languages, but need not necessarily teach them very much of a language.

Group Two was shown the site's home page. Group One was given the URL. It was explained that the focus groups were the next stage in the research, following on from the initial questionnaire.

2. Students were asked to talk generally about how they used the web, the problems they had experienced using websites, their favourite sites, elements that attracted

Table 4. Types of site nominated by students, with examples

\begin{tabular}{|c|c|c|c|}
\hline Search engines & Academic support & Enthusiasms & Magazine \\
\hline $\begin{array}{l}\text { www.google.com } \\
\text { www.yahoo.fr }\end{array}$ & $\begin{array}{l}\text { www.quia.com/ } \\
\text { www.bbc.co.uk/schools/gcsebitesize/ }\end{array}$ & $\begin{array}{l}\text { www.bto.org/migwatch } \\
\text { www.football365.com } \\
\text { www.musicindiaonline.com/ }\end{array}$ & $\begin{array}{l}\text { www.bbc.co.uk } \\
\text { www.urban75.co.uk }\end{array}$ \\
\hline $\begin{array}{l}\text { Games } \\
\text { www.jippi.com/ } \\
\text { www.ps2.co.uk/ } \\
\text { www.emupati.com/ }\end{array}$ & $\begin{array}{l}\text { Communication } \\
\text { Hotmail and MSN: } \\
\text { http://login.passport.net/uilogin.srf?id=2 }\end{array}$ & $\begin{array}{l}\text { Shopping } \\
\text { www.burton.com/ } \\
\text { www.howies.co.uk }\end{array}$ & $\begin{array}{l}\text { Other } \\
\text { www.mycathatesyou.com } \\
\text { www.neopets.com } \\
\text { www.rathergood.com/ }\end{array}$ \\
\hline
\end{tabular}


Table 3. Areas covered in feedback questionnaire

\begin{tabular}{|c|c|}
\hline 1. The look of the site & $\begin{array}{l}\text { Overall verdict } \\
\text { Aspects liked or disliked } \\
\text { Ways to improve the look }\end{array}$ \\
\hline 2. Navigation in the site & $\begin{array}{l}\text { Overall verdict } \\
\text { Any navigation difficulties experienced } \\
\text { Ways to improve navigation }\end{array}$ \\
\hline 3. The content of the language pages & $\begin{array}{l}\text { Which languages were visited } \\
\text { Best and worst things about the pages } \\
\text { Ways to improve the pages }\end{array}$ \\
\hline 4. Information about respondents & $\begin{array}{l}\text { Year group } \\
\text { School } \\
\text { Optional: Name if willing to give } \\
\text { further feedback on the site in the future. }\end{array}$ \\
\hline
\end{tabular}

them or that they found off-putting. During this discussion, they were also asked to predict the kinds of sites that had been nominated in the questionnaire.

3. Group Two only: the facilitator left the students alone for ten minutes to choose three web sites they considered to be good. The decision to leave the students while they chose their three sites arose because the facilitator wished to have no influence over the choice. Previous experience (Hughes, 2003) had shown that a focus group left alone brought up a number of topics that groups with a facilitator did not consider. The facilitator returned and the students showed the three web sites, talking about what they liked about the sites and about issues arising from this.

Finally, the students were invited to give an instant reaction to the prototype taster site, having been shown the Home Page and the first page of the Danish taster. The Danish taster was chosen because at this stage it was the most fully-developed of the five language tasters.

Focus group data was summarised as suggested by Morgan (1998). The tapes were transcribed by one member of the research team. The focus group discussions had been semi-structured, so the main areas of questioning were used as headings for the summary. Further headings were added in order to ensure that all utterances were accounted for.

\subsection{Student feedback on prototype taster web site}

Twenty-five students completed a feedback form. Five of these had also taken part in a focus group. Before doing so, they were all given a short introduction to the site and its purpose by a member of the research team or by a teacher who had previously met with the team. Then they were given up to half an hour to explore the site individually and to complete a form. The form can be viewed at: http://www.ucl.ac.uk/atlas/feedback.html. Table 3 summarises the areas covered. The responses to each question were aggregated and then summarised. 


\section{Findings}

\subsection{Types of site liked}

Figure 2 gives an overview of the kinds of site that students nominated, showing that the largest groups were Academic support, Search engines and Enthusiasms. Table 4 gives two or three examples in each category.

Google and Yahoo were the most popular search engines. Others named included Ask Jeeves, Lycos, and some target language sites. Such a high proportion nominating search engines had not been anticipated. Many people think of Google as a tool to find web sites, yet it came up again and again as a site worth mentioning in its own right. Google was also chosen as one of three sites to talk about by the second focus group. In Section 4 the possible implications of this are considered.

By far the most popular site for helping with school work was the BBC's GCSE Bitesize site. This partly reflects the population surveyed, more than half of whom were in the right age-group ${ }^{2}$ for that site. However, some language support sites were also mentioned.

The Enthusiasms category contained many different sites. Music and sport were the largest sub-categories and, within these, fan sites for individual teams, bands and performers were mixed with sites dedicated to one type of music or to one sport. The Magazine category represents sites that cover many different subjects, as a magazine does. The BBCi web site, and Urban75, a magazine with a political emphasis, were two examples. Games - to play online or to download - were mentioned often. Shopping was another important category; fashion items were popular but students were also attracted by unusual items, perhaps difficult to obtain in shops. A Heritage sub-category might have been created (and was considered) under some of these headings, to include, for example Armenian and Indian music sites, Russian and Spanish Games sites, a Chinese discussion forum. This is probably a reflection of the multi-cultural population of the schools involved; the web seems to be one way that students stay in touch with their family's heritage.

The final category was Communication. It is clear that these students used the web a great deal for communication (in the focus groups, some of the year 12 students said that this was the only use they made of it). Specifically, email, chat and text messaging sites were mentioned.

Later, the focus group students predicted quite accurately the types of site nominated in the questionnaire but they suggested two further categories: review sites (film and music); mobile phone ring tones.

\subsection{Reasons for liking sites}

By far the most common type of reason students gave for liking a site was its function or content. For example, search engines were valued for being able to find information, email sites for offering communication, other sites because the content was interesting or useful. Between them, reasons associated with content and function were almost as common as all other kinds of reasons combined (see Figure 3).

2 GCSE is a national examination taken by $15-16$ year olds in England and Wales. 


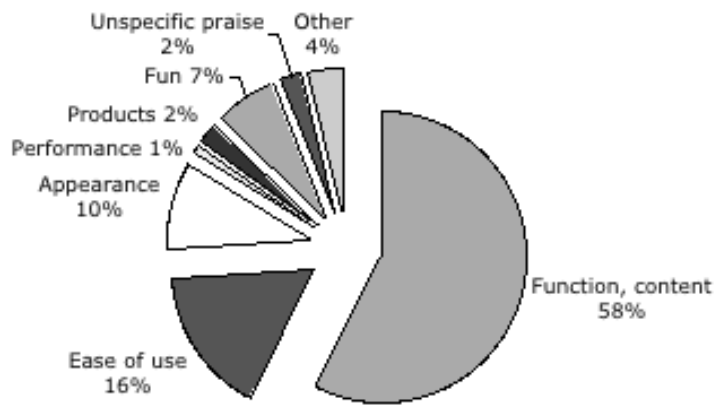

Fig. 3. Reasons for liking sites (questionnaire).

The next most frequently-given reason was ease of use. This reason was most often associated with a search engine. Aspects of the appearance of the site occurred quite frequently across all types of site. Colour and layout were the most common attributes mentioned, followed by graphics and pictures. Fun seemed also to be an important factor; most of the reasons in this category involved activity/interactivity or humour. Very few students cited fast or efficient performance as a reason for liking a site.

It had been decided to aim for only a small number of categories for the analysis. Having made this decision, two areas caused some discussion. The fact that it offered help with school work was often given as a reason for liking a web site. It was decided to treat this group of reasons as a sub-category of function and content. Sites that offered interaction and feedback seemed to be particularly valued, with the most common interaction being practice assessments. Secondly, "It's hilarious", "It's funny" occurred quite frequently. We put these into the Fun category, but it might be worth considering whether this was the right decision.

Under "Other" are reasons that were not understood, as well as those that did not fit into any category.

\subsection{Exploring the reasons in focus groups}

\subsubsection{Text}

While the questionnaire asked for positive nominations of web sites, the focus groups gave students the opportunity to talk about negative aspects of using the web, as well as about what they liked. "Lots of text" was unanimously agreed to be off-putting, in both groups. However, when this idea was explored, it emerged that it was not the quantity but the arrangement of text that mattered. Students actually liked pages that were quite densely packed with text, provided that the text was divided into small blocks, clearly headlined, and separated from one another. In line with the Nielsen (2000) guidelines, it was clear that they wanted to scan, not read the text, and there was mention of "searching" the page.

The desire to scan and search is also evident in the fact that the focus group students liked to have lots of links on a page but wanted to know, before clicking on them, what they would find, as with an annotated bibliography. They pointed to the BBCi site 
(Figure 4) as an illustration of good arrangement of text and good presentation of links. This may also explain why several other sites containing "lots of text" were nominated in the questionnaire.

\subsubsection{Visual attributes}

Colour is the most frequently mentioned visual attribute in the questionnaire responses but receives even more attention when students have a web page in front of them, as they did during the second focus group and when they gave feedback on the taster website. The students emerged as very sensitive readers of colours and pictures. They stated that they liked an effect that was "eye-catching" but "not too in your face". Further than this, they perceived the use of certain colours to be "patronising". This perception was evident in their talk about web sites (including the prototype taster site). Group Two used the BBCi site (Figure 4) as illustration. They stated that it had about the right number of pictures. They seemed to be aware of assumptions that web designers were making about them. They particularly liked the BBCi colour scheme, which was described as "subtle". They contrasted this with the BBC school site (Figure 5), whose bright colours they felt spoke to them as "kids".

Group Two also made a distinction between the use of photographs, which they said appealed to "older teens" and cartoons of "space ships and monsters", which they saw as being for younger children. However, this issue is not straightforward. Cartoons were also perceived as fun and funny, and hence as positive attributes in a web site.

Page layout also seemed important to the students. It was mentioned in both questionnaires and focus groups. Simplicity and lack of clutter were valued - and this was a reason given for liking Google more than Yahoo. However, they liked all space to be used, and commented adversely on the white space around the map on the prototype taster home page (Figure 6a).

Finally - and again perhaps contrary to what is assumed about designing web sites for this age group - some visual effects were not liked by either focus group. They mentioned in particular, "Things that mess up your eyes": backgrounds, blinking, or flashing.

\subsubsection{Other points from focus groups}

Students also stated that having to drill down through page after page was annoying. They were irritated by some sounds and by music that could not be turned off, and they disliked having to download helper applications, such as Flash and Acrobat Reader.

\subsection{The impact of our findings on design decisions}

\subsubsection{Design fundamentals and specifics}

At the planning stages of the project, the team envisaged the taster web site as being focused on giving its users a taste of language learning, but it also needed to 'sell' languages to potential university students. It was therefore drawing on design for learning and teaching, but we suspected that it might also need some elements of design for commercial purposes, and that these could be drawn from some relevant sources (including 


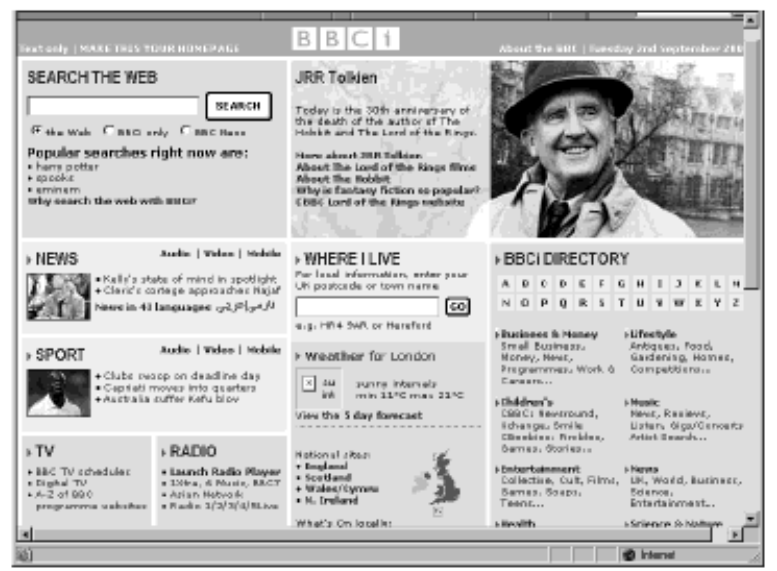

Fig. 4. BBCi home page. This is composed of neutral cream and beige colours (hexadecimal codes for the principal colours on the page: C9B591, EDDDC9, F7EEE4).

Nielsen, 2000; Cotler \& Goto, 2003). Draft design ideas were influenced by commercial web sites. In terms of content, we looked for subjects from popular culture which we thought would appeal to the students. We foresaw a number of potential difficulties, namely the difficulty of attracting this age-range to spend time on something which was non-compulsory, and with a limited budget to provide a site which could compete with so many others. However, specific design decisions were not taken until the initial research had been conducted via the student survey. The research contributed to a number of design decisions, first in the development of the 'prototype' site, and then in refining this to become a formal pilot site after our focus groups. The process of balancing elements of design in terms of the students' preferences and our purposes challenged many of our initial assumptions about how the tasters should look and function, and the

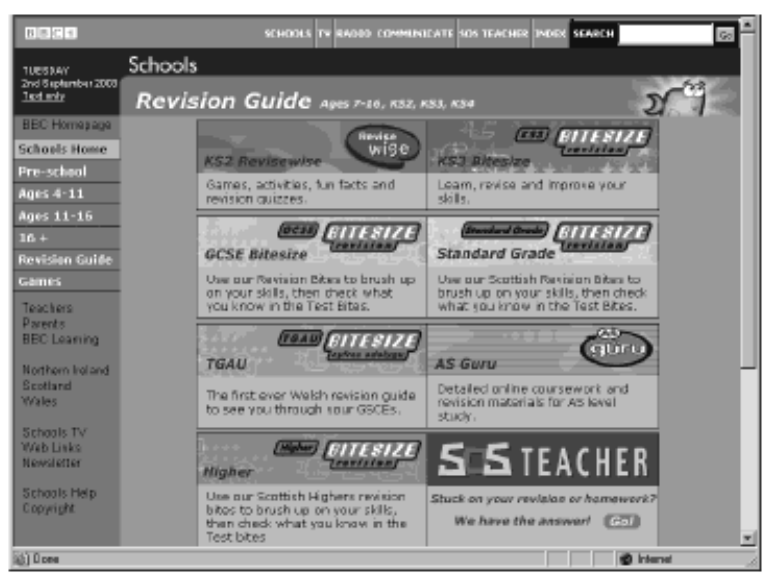

Fig. 5. BBC Schools Home Page, September 2003. This is is designed in bright orange, yellow and red colours. The main layout of the page uses the hexadecimal colours FFA000, FF6E00, A00000. 


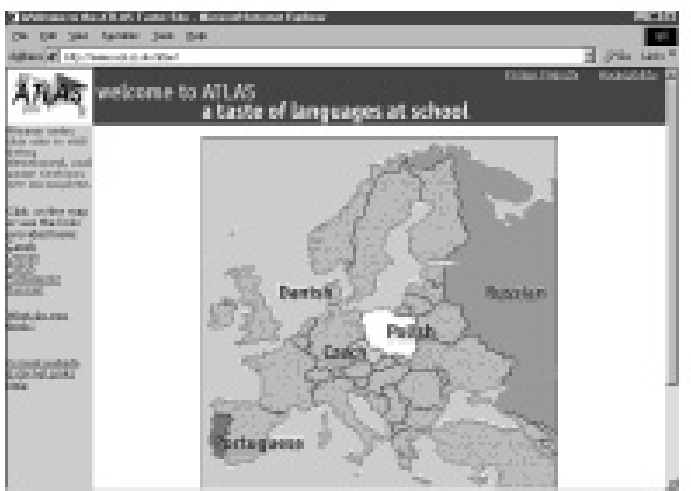

Fig. 6a. The prototype taster homepage.

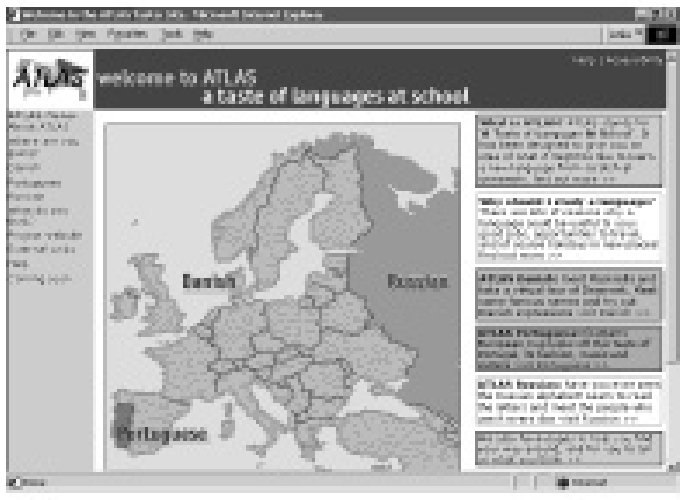

Fig. 6b. The pilot taster homepage.

kinds of content they would have.

It quickly became clear from our research that students favoured sites which had been constructed according to accepted good practice for web design. They liked clarity of function and content, and clear navigation. They did not like gimmicks such as 'pop-up' windows with animations or 'blink' features, scrolling text or similar. These features are not advocated in web design practice either (Lemay, 2000; Nielsen, 2000).

However, interpreting some of their other reasons for liking or disliking sites, and bringing these into our design, proved to be more complex. The overall management of design and content to create an engaging, attractive site for this audience without its being perceived as gimmicky or patronising, was a complicated process.

\subsubsection{Text}

The research raised interesting questions about the management of text on the site. It was important to consider the function of different websites the students preferred before considering how those sites had managed text. For example, the survey indicated 
that they liked the simple interface of Google, but it has a very specific function as a search engine. Keeping the prototype homepage (shown in Figure ga) very simple, we then found in the focus groups that these students did not like the large areas of white space. The focus groups revealed that they liked lots of short, scannable pieces of text on other kinds of site (for example BBCi). In addition, they wanted descriptive information about the content of different links on the site, and to know what they might be likely to find if they followed particular links. They were also distinguishing between links made for navigation and those made to introduce other parts of a website. On this basis, the next version of the homepage made for the pilot (shown in Figure 6b), and later on, pages within the language tasters, were redesigned to include short, scannable pieces of information and details of what was behind the links.

The students' preference for text in blocks, headlined and separated clearly, was also built into our design. This entailed working with teachers on some of the content they produced, but also giving attention to the size of sections and sub-sections of the site, and ensuring that pages were 'chunked' wherever possible.

Size and format of text were also important issues. The original stylesheet used for the prototype site (before the focus groups) did not display text at different sizes on different screen resolutions. Neither had testing been completed at this stage. Some of the students at our focus groups subsequently found that the text was too small and could not be read easily. Although this was partly due to the early stage of development, it was nonetheless a little surprising as many of the sites they had included in their survey responses displayed text in very small sizes. Therefore, testing was continued but the stylesheet was also adjusted.

In terms of font choice, Verdana (a sans-serif font) has been used throughout the text of the taster site. It has been used as it is a font designed specifically for the web, but also because sans-serif fonts facilitate legibility for users with dyslexia. However, further research could be done to discover the students' responses to this specific font: its widespread use may be perceived as over-use by web-literate groups such as this one. It is also worth noting that some of the sites named by students in the survey used Times Roman and other fonts which were the only ones available when the web was first developed. It may be interesting to explore whether these 'traditional' web fonts have particular connotations for students. A focus group reference to "boring fonts" hints that this idea could be worth pursuing. For text within graphics, the font Officina was used as this is a font common in many web and paper-based publications targeted at this age range. The students' reactions to this font could be compared with those to 'traditional' web fonts in future research.

\subsubsection{Visual attributes}

The students' nominated websites as well as a selection of magazines, television and other media were useful to a certain extent in giving the team a flavour of how other people used layout, colour and graphics in designing for this audience. The prototype site incorporated some of these design elements and had very different colour schemes, graphics and styles for each language although the overall layout was kept consistent from an early stage. 
Reference to other print and web-based media designed for this age range was also helpful in choosing colours and graphics for the site, although there was a process of refinement of our choices as we learned more from the students at our focus groups. The websites students cited in the survey tended towards having bright colour schemes for 'younger' sites (for example, the Bubble Gum Club and Barbie websites) and for some educational sites (e.g. GCSE Bitesize) and darker colours, very often black, for 'older' or less mainstream sites (e.g. those for alternative fashion or music). Further discussions on this issue in the focus groups helped us to select colours for the pilot site that would appeal to this age group without seeming patronising. Therefore, the site has been developed with no extremes from the colour spectrum, but a combination of neutral tones for its main and 'Help' pages, and a separate mid-range colour for each language. These design decisions are aimed at giving each language an identity while keeping a consistent overall colour scheme to the site.

In light of students' responses to different kinds of graphics, we have used cartoons illustratively and mainly to convey humour in the site, rather than attributing functionality to them. The only exception to this is the cartoon mermaid for Danish who catches fish, each of which leads to a different area of the site when clicked. This cartoon has been retained partly for practical reasons (as development of this feature was at a more advanced stage before the focus groups were conducted). However, it will be reconsidered in the light of further student feedback on the site, in the evaluation phase of the project.

Photographs have also been used extensively to help give short 'virtual tours' of the countries in which the taster languages are spoken. Interestingly, the students have asked that the site have more photos of people, and we had been aware of the scarcity of people in the pictures we selected. The difficulty had been that, under the terms of the UK's Data Protection Act (1998) we are obliged to have consent from individuals in photographs being made available on the internet and this was not always possible in the case of photographs taken by the teachers on holiday in the target language countries. Maps have been used at several points in the site, and the main map on the prototype homepage received a favourable response in the focus groups. However, there are issues for us to consider further, in our evaluation, in relation to the use of maps. Some of the taster languages are spoken in many other countries outside the ones with which we associate them. The map is a useful means of organising materials in the first instance, but we have also included mention within each taster of other places in which the languages are used.

\subsubsection{Interactive elements}

Findings from our research showed that students particularly liked sites that facilitated communication (via email) with others. The taster site has been planned with a view to encouraging some communication between potential language students and the language teachers who prepared materials. This is dependent to some extent on the teachers' availability to respond to student communications, and is via email. Although the site has not been designed to provide discussion or chat facilities, the team will encourage this communicative function.

All the teachers felt that it was important to include some features on the site that would allow the students to interact with the content. This was to help engage the students and to 
reflect their interest in games, quizzes and 'fun' while online. In some areas of the site, this interactivity is rudimentary, with a single multiple choice question to open a topic. For other topics, there are simple exercises in the taster language - for example, one in Danish to translate short phrases which include words similar in English and Danish. These exercises have been designed also to demystify the language and to show students that they may already know a few words, and can pick up simple phrases quickly.

\subsubsection{Multimedia}

Aside from animations, the pilot taster courses contain some brief sound files but no video. This has been determined partly by the availability of multimedia content. Teachers have been able to make short audio recordings for digitisation and inclusion on the site. However, it was not a straightforward process for them to make or digitise video footage within the limited resources of the project, and it was difficult to obtain copyright clearance for video of films or television programmes to be relayed on a publicly available website which was not supporting a formal course. However, it has been interesting to note that students have not mentioned the lack of video, nor the small number of sound files in their feedback to us. It is also important to note that they also expressed a dislike for having to obtain additional 'plug-in' software when using the web. This was somewhat unexpected as our initial plans for the tasters envisaged that students would have welcomed sophisticated resources of this kind, whereas our research with them has indicated that it may not be of primary concern.

\subsubsection{Content}

Specific decisions about content could only be taken when the language teachers began to draft their materials. They were given the freedom to choose topics for their tasters, and we did not insist on a uniform structure within each language's webpages. This was a condition of the design from the outset, as it would not have been practical to impose such a structure where teachers were working at a distance from each other and on a part-time basis, in some cases having to adapt material they already had. The team suggested topics we thought would be appropriate (including football, celebrity culture, music and fashion) but the teachers also brought their own themes (for example, immigrant culture in the UK associated with their languages). The wide range of hobbies, enthusiasms and cultural interests reflected in the websites cited by students in our survey lent support to our decision that the site should reflect teachers' own interests. In fact, subject matter which was unusual or alternative was valued by many students and we concluded that the unusual nature of the taster languages would be very positive.

\section{Conclusions and discussion}

Throughout the design process, we considered the aspects of good web design, and good resource design for learning and teaching, that would support the creation of a successful taster site: 
- Good usability, clear functionality and navigation.

- Design for accessibility by all visitors to the site.

- $\quad$ Providing opportunities for social interaction and interaction in learning.

- Clarity and consistency in the management of text and subject matter.

- Reflection of the teachers' interests and their perspectives on how to convey the taster languages to this audience.

In addition, the research we have undertaken into what students like about websites has demonstrated to us the importance of considering carefully the overall visual impact of this site, and the management of its visual elements. Becoming aware of the visual literacy of the potential audience for the taster courses has challenged some of our preconceptions for the design.

It is clear that what language teachers already know about designing learning materials also applies to creating web-based resources. Interesting, varied content, opportunities to interact with the content and with other people, information about the culture of the country as well as the language, go a long way towards providing a good learning experience for students. Templates provided by their institutions, or through authoring and virtual learning environment tools, can help teachers to make web pages accessible and usable for all students, without having to grapple with technical standards. However, teachers probably do need to be aware of what students bring to their reading of web content and of how this may be changing. The students who participated in this research are alive to visual messages, to which teachers may be less sensitive. They may read a lot into the choice of font, colours and graphics. Students in this age group can also be particularly sensitive to condescension and teachers should know that they may perceive this not only in the level and content of learning materials, and the way in which the text addresses them, but also in the visual elements.

There may be also be implications for learning with printed materials. In the past, teachers of English (for example) had to take steps to encourage even confident readers to develop scanning and skimming skills; now these have been developed to a high degree in students who use the web. They may therefore bring to book texts different expectations from those of past students, which, in turn, may alter classroom approaches to printed text.

Another possible area of discussion concerns students' use of search engines. The proliferation of search engines in the questionnaire responses came as an initial surprise but, in retrospect, ought not to have done. Both focus groups were asked how they found websites. Teachers did recommend sites but the picture that emerged was of a subject teacher recommending a single site and, in some cases, one that students had not liked or found useful. Teachers' own education and experience is likely to have given them a broad grasp of the print resources in their field; they can recommend a range of book resources and suggest to their students which ones will suit particular needs. However, they may well not have the same confidence and command in relation to online resources. Indeed, the web changes so rapidly that it is possible teachers will never have the same overview of what is available and that students will continue to find support for their schoolwork by exploring the web for themselves.

The two groups of students interviewed found some websites from friends' recom- 
mendations, from magazines and from pop-ups on sites they already knew. But they also relied heavily on searching the web. They were aware that searches could be more and less efficient and that the results were not always what they needed, so this group of students might benefit from tools to support the process and to help them to evaluate sites that they find. Those who design learning materials that may be publicly available for "discovery" might also take note of the need to make a page "eye catching" without its being perceived as "too in your face" or "patronising". One might also wonder about the role of visual elements in students' perceptions of whether a language learning or other educational site, encountered when browsing or searching, is reliable or authoritative (see Section 5).

Finally, it is important to be aware of the snapshot nature of any research in this rapidly changing area. Very soon, this group of students will enter higher education and younger children still, whose visual literacy has been developed throughout their educational lives, will take their places in schools. We suggest that this area of enquiry is likely to become increasingly important and that teachers and designers at all levels will need to keep adjusting to a changing audience. The research therefore has relevance to the design of online learning for a wider age range than the school students who were the subjects here.

\section{Future work}

The ATLAS Taster site is now being used in schools but it will continue to be developed, responding to further feedback from students and teachers. It was used by four schools during November and December 2003, and released again to the project's nine partner schools in January 2004.

Further research will be undertaken with students and teachers while the site is in use. This will aim both to determine whether the experience of using the taster site does foster positive attitudes towards learning foreign languages, and to follow up the work reported here. More research will be conducted into students' reading of web pages. Their relationship with search engines and other aspects of their exploration of the web will be investigated; this will include consideration of how non-textual elements affect students' perception of whether an educational site can be trusted. Finally, in collaboration with colleagues in other countries, we hope to find out whether there are cultural differences in students' likes and dislikes in web sites.

\section{Acknowledgements}

The ATLAS project is funded by: The Nuffield Foundation, CfBT Research \& Development and University College London (UCL). We would like to thank staff and students in our Partner Schools: Ashcombe School, Surrey; City and Islington College, London; Cranford Community College, Hounslow; Elliott School, London; Haverstock School, London; Haydon School, Pinner; Parliament Hill School, London; Weald of Kent Grammar School for Girls, Kent; William Ellis School, London. Many thanks also to the language teachers who have developed the tasters: Lydia Buravova, Jannie Roed, Maria Gilham, Dorota Holowiak, Allan J. Kristensen, and David Short. 


\section{References}

ATLAS Project. http://www.ucl.ac.uk/epd/atlas/

Brown, I. (2003) The case of the forgotten pedagogy: the value of visual literacy for learning with new technologies. Proceedings of CAL (Computers and Learning) 2003, Queen's University Belfast, 8-10 April 2003.

Goto, K. and Cotler, E. (2002) Web ReDesign: Workflow that Works. Indianapolis: New Riders.

Hémard, D. and Cushion, S (2001) Evaluation of a web-based language learning environment: the importance of a user-centred design approach for CALL. ReCALL 13(1): 15-31.

Hinostroza, J. E. and Mellar, H. (2001) Pedagogy embedded in software design: report of a case study. Computers and Education 37: 27-40.

Honeywill, P. (1999) Visual Language for the World Wide Web. Exeter: Intellect.

Hughes, (2003) A Shared Workspace for Text-based Teaching and Learning: Design Requirements and Pedagogical Benefits. Unpublished $\mathrm{PhD}$ thesis, University of London.

The Joint Council for General Qualifications (JCGQ) http://www.jcgq.og.uk/

Kelly, M. and Jones, D. (2003) A new landscape for languages. London: Nuffield Languages Programme. http://www.nuffieldfoundation.org/languages/news/nw0000000548.asp. Last accessed 5th April 2004.

Kensing, F. and Munk-Madsen, A. (1993) PD: Structure in the Toolbox. Communications of the $A C M$ 36(4): 78-85. Special issue on participatory design.

Kress, G. (1998) Visual and verbal modes of representation in electronically mediated communication: the potentials of new forms of text. In: Synder, I., Page to Screen: Taking Literacy into the Electronic Era. London: Routledge, 53-79.

Lemay, L. (2000) Teach Yourself Web Publishing with HTML 4.0 in 21 Days. Indianapolis: Sams

Lunt, P. and Livingstone, S. (1996) Rethinking the focus group in media and communications research. Journal of Communication 46(2): 79-98.

Morgan, D. L. (1998) The Focus Group Guidebook. Focus Group Kit Volume 1. Thousand Oaks, CA: Sage.

Muller, M. J., Wildman, D. M. and White, E. A. (1993) Taxonomy of PD practices: a brief practitioner's guide. Communications of the ACM, 36(4): 64-66. Special issue on participatory design,

Nielsen, J. (2000) Designing Web Usability: The Practice of Simplicity. Indianapolis: New Riders.

Ritchie, D. C. and Hoffman, R. (1996) Using instructional design principles to amplify learning on the world wide web. Technology and Teacher Education Annual, Proceedings of SITE96: AACE.

Rowntree, D. (1994) Preparing Materials for Open, Distance and Flexible Learning. London: Kogan Page.

Sims, E., O’Leary, R., Cook, J. and Butland, G. (2002) Visual lLiteracy: What is it and do we need it to use learning technologies effectively? Proceedings of ASCILITE 2002, 885-888.

Wall, P. and Mosher, A. (1994) Representations of work: bringing designers and users together. Proceedings of PD'94, the Participatory Design Conference, Chapel Hill, North Carolina. CPSR (Computer Professionals for Social Responsibility), Palo Alto, CA, 87-98.

Weinman, L. (2003) Designing Web Graphics 4. Indianapolis: New Riders. 